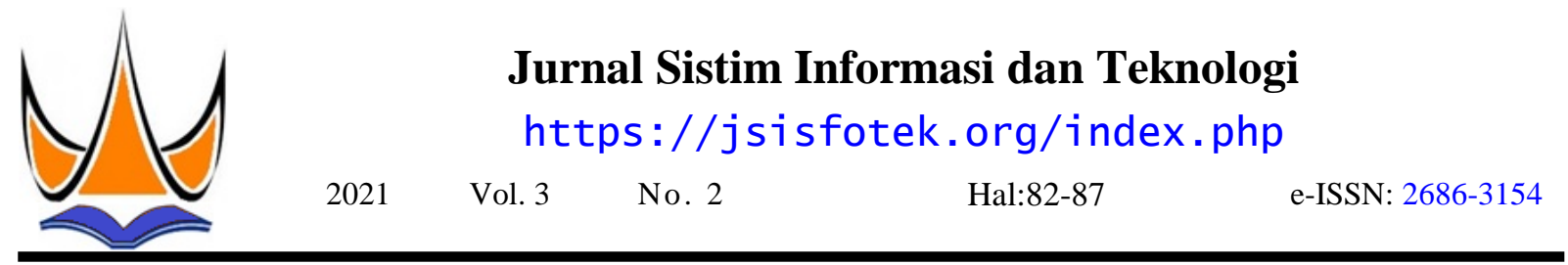

\title{
Rancang Bangun Alat Penampung Buku Berbasis Arduino pada Sistem Pengembalian Buku Layanan Mandiri
}

\author{
Emil Naf'an ${ }^{1 \otimes}$ \\ ${ }^{1}$ Universitas Putra Indonesia YPTK Padang \\ emi1nafan@upiyptk.ac.id
}

\begin{abstract}
This study aims to design and create a book container in a self-service book return system at the Andalusia Library \& Knowledge Center UPI YPTK Padang. Currently, the self-service book return system is carried out through a book drop machine. This book container is designed to complement the book drop machine. The returned book is inserted into the slanted gap so that it can slide into the book container. When the book container is empty, the base is at the upper limit position. If a book is entered, the base will automatically drop according to the thickness of the book. And so on, until it is full and the buzzer is active. Thus, it is hoped that book damage can be prevented due to the book falling too far down. The system is designed using ultrasonic sensors to detect upper and lower limits, a Direct Current (DC) motor to move the base down according to the thickness of the book. After testing, the book container works well and is able to withstand loads of up to $22 \mathrm{~kg}$ with the number of books between 30 and 50 depending on the size of the book. The DC motor is able to move the book container when the load is maximum. The sensor can detect the thickness of the book, the upper and lower limits and the buzzer can activate when the book is full. Thus, this tool can be used to support the book drop in the self-service book return system.
\end{abstract}

Keywords: Book Container, Ultrasonic Sensor, Arduino, Motor DC, Buzzer.

\begin{abstract}
Abstrak
Penelitian ini bertujuan untuk merancang dan membuat alat Penampung Buku pada sistem pengembalian buku layanan mandiri. Tempat penelitian pada Andalusia Library \& Knowledge Center UPI YPTK Padang. Saat ini sistem pengembalian buku layanan mandiri dilakukan melalui mesin book drop. Alat yang dirancang berfungsi sebagai pelengkap mesin book drop tersebut. Buku yang ingin dikembalikan dimasukkan ke dalam celah yang dibuat miring, sehingga buku bisa meluncur ke tempat penampung buku. Saat alat penampung buku kosong, alas penampung buku berada pada posisi batas atas. Jika ada buku yang masuk, maka alas tersebut secara otomatis turun sesuai dengan ketebalan buku. Proses berlanjut sampai alat penampung buku penuh dan buzzer aktif. Dengan demikian diharapkan kerusakan buku dapat dicegah akibat buku jatuh terlalu jauh ke bawah. Sistem yang dirancang menggunakan sensor ultrasonik untuk mendeteksi batas atas dan batas bawah. Berdasarkan data sensor tersebut, arduino mengirimkan sinyal ke motor Direct Current (DC) untuk menggerakkan alas penampung buku ke bawah sesuai dengan ketebalan buku. Jadi setiap buku yang masuk selalu berada pada posisi batas atas dan menjadi alas bagi buku yang masuk berikutnya. Setelah dilakukan pengujian, alat penampung buku dapat bekerja dengan baik dan mampu menahan beban hingga $22 \mathrm{~kg}$ dengan jumlah buku antara 30 hingga 50 buah buku tergantung kepada besar kecilnya buku tersebut. Motor DC mampu menggerakkan alas penampung saat beban maksimal. Sensor ultrasonik dapat mendeteksi ketebalan buku, batas atas maupun batas bawah serta buzzer mampu aktif saat buku sudah penuh. Dengan demikian alat ini dapat digunakan sebagai pendukung book drop pada sistem pengembalian buku layanan mandiri tersebut.
\end{abstract}

Kata kunci: Penampung Buku, Sensor Ultrasonik, Arduino, Motor DC, Buzzer.

(C) 2021JSisfotek

\section{Pendahuluan}

Buku merupakan salah satu sumber dalam menambah ilmu pengetahuan [1]. Hadirnya e-book dan sumber Saat ini di Andalusia Library Center, proses bacaan elektronik lainnya melalui internet saat ini tidak pengembalian buku yang dipinjam bisa dilakukan serta merta begitu saja bisa menggantikan posisi buku dengan dua cara. Cara pertama yaitu dengan di hati pembacanya. Oleh sebab itu pada setiap mengembalikan langsung ke petugas perpustakaan. perpustakaan, ketersediaan buku merupakan sesuatu Cara kedua yaitu dengan mengembalikan buku melalui yang mesti ada [2]. Begitu juga halnya dengan mesin book drop. Penggunaan mesin book drop ini ketersediaan buku pada Andalusia Library yang terletak cukup mudah. Buku yang ingin dikembalikan di Kampus Universitas Putra Indonesia YPTK Padang dimasukkan ke dalam celah. Pada monitor akan tampil propinsi Sumatera Barat. Andalusia Library \& data buku tersebut. Jika buku yang dipinjam lebih dari Knowledge Center ini memiliki relatif banyak koleksi satu, maka buku harus dimasukkan satu persatu. Jika buku. Setiap mahasiswa boleh memanfaatkan fasilitas sudah selesai maka resi pengembalian buku akan 
dicetak sebagai bukti pengembalian buku yang sensor ultrasonik disebabkan kemampuan sensor untuk dipinjam. Celah tersebut dibuat miring, sehingga buku mendeteksi jarak tanpa harus bersinggungan dengan bisa meluncur ke tempat penampung buku. Diujung benda yang diukur [8]. Disamping itu akurasi sensor celah tersebut terdapat tempat penampung buku yang ultrasonik relatif bagus, sehingga cocok digunakan secara otomatis turun sesuai dengan tebal buku yang untuk alat yang dirancang [9], [10]. Untuk menggerakdimasukkan. Hal ini berguna untuk mencegah kan sistem mekanik alat penampung buku digunakan kerusakan buku, karena jika buku terlalu jauh terjatuh motor DC berdaya rendah [11] [12]. Sebagai penanda menuju alas penampung buku, dikhawatirkan buku buku telah penuh dalam alat penampung, dalam hal ini lebih cepat rusak [3]. Jadi alat penampung buku yang digunakan buzzer [13]. Semua peralatan dikendalikan dirancang berfungsi sebagai pelengkap mesin book oleh modul Arduino berdasarkan program yang drop tersebut.

Alat penampung buku ini sudah pernah ada sebelumnya pada Andalusia Library \& Knowledge Center UPI YPTK Padang, namun memiliki kelemahan yaitu tidak sanggup menampung buku yang relatif banyak. Hanya lebih kurang 10 buah buku saja. Disamping itu sistem ini sering tidak kuat menampung buku dengan berat tersebut dan terkadang hanya 5 buah buku saja, buzzer penanda buku sudah penuh sudah aktif. Hal ini tentu saja merepotkan petugas pustaka, karena harus sering mengambil buku yang terletak di penampung buku tersebut. Jika tidak diambil, maka pengembalian layan buku layanan mandiri tidak bisa dilakukan, karena penampung buku sudah penuh. Seiring dengan meningkatnya minat baca, maka proses sirkulasi buku juga meningkat. Rata-rata pengembalian buku setiap hari lebih dari 10 buah buku. Dengan demikian sistem yang lama harus dirancang dan dibuat ulang, sehingga bisa menampung buku hingga mencapai antara 30 sampai dengan 50 buah buku.

Alat penampung buku sudah ada diteliti oleh beberapa peneliti dan bahkan ada yang dijual lengkap bersama dengan book drop nya, namun harganya relatif mahal [4]. Pada penelitian yang dilakukan oleh Tjandrarini [5] dilakukan pembuatan prototipe tempat dan aplikasi pengembalian koleksi perpustakaan secara mandiri. Namun dalam penelitian prototipe alat yang dibuat masih dalam bentuk rangkaian elektronik dan tidak terdapat sistem mekanik dalam pengaturan penampung buku yang dikembalikan.

Penelitian yang lain dilakukan oleh Muhammad Aria [5]. Pada sistem ini sudah terdapat desain alat penampung buku. Namun juga tidak terdapat sistem mekanik dalam pengaturan penampung buku yang dikembalikan. Artinya buku yang dikembalikan dibiarkan jatuh begitu saja dalam book drop. Jika tinggi book drop lebih kurang $60 \mathrm{~cm}$ sampai dengan $80 \mathrm{~cm}$, itu artinya jika tempat penampung masih kosong, buku akan jatuh terlalu jauh. Jika ini sering terjadi, maka kerusakan buku dalam jangka waktu yang relatif dekat kemungkinan besar pasti terjadi.

Untuk itu diperlukan suatu sistem penampung buku yang secara otomatis mampu menjaga agar buku tidak jatuh terlalu jauh. Dalam penelitian ini dibuat sistem mekanik yang berfungsi untuk itu. Sistem menggunakan tombol input $1 . .4$ yang berfungsi sebagai input untuk pengendalian peralatan secara manual [6], [7]. Untuk mendeteksi batas atas dan bawah alat penampung digunakan sensor ultrasonik. Pemilihan tersimpan di dalam Memory Program Arduino tersebut. Pemilihan Arduino berdasarkan kemampuannya dalam mengendalikan peralatan [14] [15][16][17].

\section{Metodologi Penelitian}

Penelitian ini bertujuan untuk merancang dan membuat suatu sistem berupa alat Penampung Buku menggunakan Arduino sebagai pengendali pada Sistem Pengembalian Buku Layanan Mandiri. Metode yang dilakukan dalam penelitian ini yaitu : Perancangan Sistem, Implementasi Sistem dan Pengujian Sistem. Dari hasil pembahasan terhadap pengujian yang dilakukan, diperoleh kesimpulan dari sistem yang dirancang.

\subsection{Perancangan Sistem}

Dalam melakukan perancangan sistem terdapat dua hal yang perlu dilakukan yaitu perancangan dari segi perangkat keras (hardware) maupun perangkat lunak (software). Perancangan tersebut didasari atas ketentuan sebagai berikut:

a. Sistem harus mampu menampung buku antara 30 sampai dengan 50 buah.

b. Pada saat buku dimasukkan ke dalam alat penampung buku, sistem harus mampu menurunkan buku secara otomatis pada batas atas, sehingga alat penampung bisa menampung buku berikutnya yang dimasukkan oleh si peminjam buku.

c. Sistem harus mampu mendeteksi bahwa buku telah penuh pada alat penampung dan mengaktifkan buzzer untuk memberitahu petugas agar memindahkan buku tersebut ke tempat yang telah ditentukan.

d. Sistem harus dilengkapi dengan pengaturan peralatan secara manual menggunakan tombol pengaturan sistem.

Adapun blok diagram dari sistem yang dirancang dapat dilihat pada Gambar 1. Pada blok diagram tersebut terlihat bahwa sistem yang dirancang menggunakan modul Arduino Mega2560 sebagai pengendali. Tombol input berfungsi sebagai input dalam proses setting peralatan secara manual. Tombol ini terdiri dari 4 buah tombol, yaitu tombol turun per step (langkah), tombol turun sampai ke posisi batas bawah, tombol naik per step, tombol naik sampai ke posisi atas alat penampung.

Jurnal Sistim Informasi dan Teknologi Vol. 3 No. 2 (2021) 76-81 


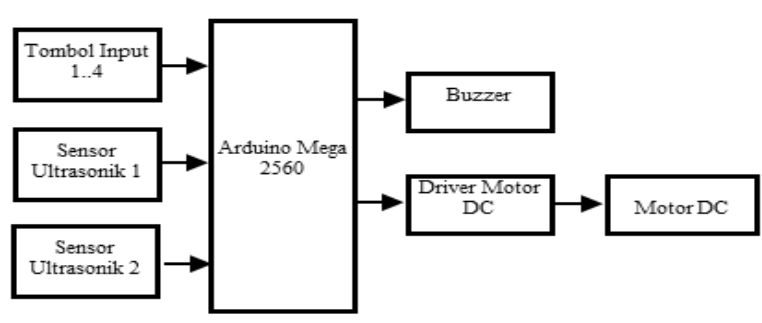

Gambar 1. Blok Diagram Alat Penampung Buku

Sensor ultrasonik 1 berfungsi untuk mendeteksi batas atas daripada alat penampung buku. Sedangkan sensor ultrasonik 2 berfungsi untuk mendeteksi batas bawahnya. Pada saat buku telah penuh di dalam alat penampung, maka posisi alas alat penampung akan berada pada bagian bawah. Hal ini akan memicu sensor ultrasonik 2 bekerja. Sensor akan mengirimkan sinyal ke Arduino Mega2560 agar mengaktifkan buzzer sebagai penanda buku telah penuh. Motor DC berfungsi sebagai penggerak sistem mekanik peralatan penampung buku agar bergerak turun maupun naik. Motor DC ini memerlukan driver Motor DC agar bisa bekerja dengan baik. Keseluruhan sistem dikendalikan oleh Arduino Mega2560, dengan dibantu oleh Arduino Uno R3 berdasarkan data yang tersimpan dalam memory program modul tersebut.

\subsection{Implementasi Sistem}

Pada tahap ini dilakukan implementasi dari sistem yang telah dirancang. Implementasi sistem dilakukan dengan membangun perangkat (alat) yang telah dirancang sebelumnya baik dari segi perangkat keras (hardware) maupun perangkat lunak (software). Dari segi perangkat keras (hardware), alat penampung buku ini dibangun mulai dari pembuatan rangkaian elektronik dan pembuatan rangka alumunium serta pembuatan sistem mekanik alat penampung tersebut.

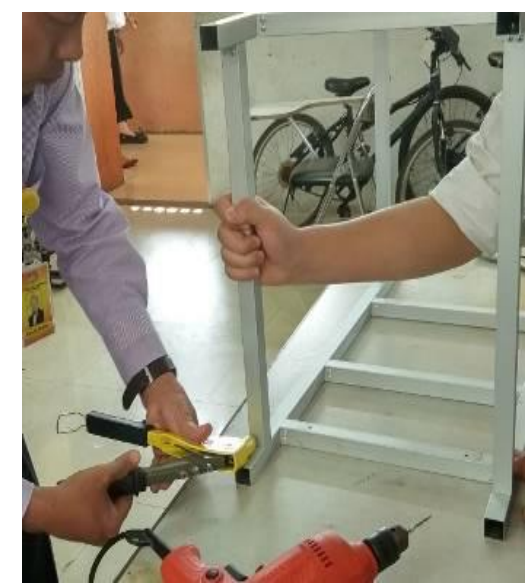

Gambar 2. Proses pembuatan Rangka Aluminium

Hal yang perlu diperhatikan dalam pembuatan rangka aluminium antara lain ; ketelitian dalam mengukur dan memotong aluminium tersebut. Disamping itu dalam proses pengeboran aluminium dan pemasangan menggunakan tank rivetnya hendaklah diperhatikan ketepatan sudut siku aluminium, harus membentuk sudut 90 derajat. Dokumentasi pembuatan rangka aluminium dapat dilihat pada Gambar 2.
Selanjutnya dalam proses pembuatan mekanik, pada tahap awal dilakukan pemasangan gear pada As drat galvanis Putih diameter $20 \mathrm{~mm}$. Gear tersebut dilaskan pada ujung sumbu drat. Penggunaan gear tersebut adalah untuk meningkatkan torsi motor, sehingga mampu menggerakkan alas penampung buku walaupun memiliki beban yang relatif berat.

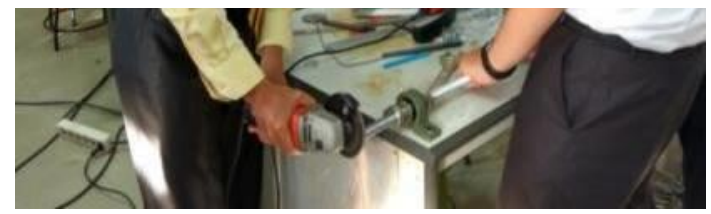

(a)

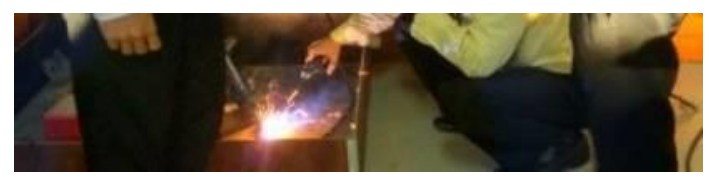

(b)

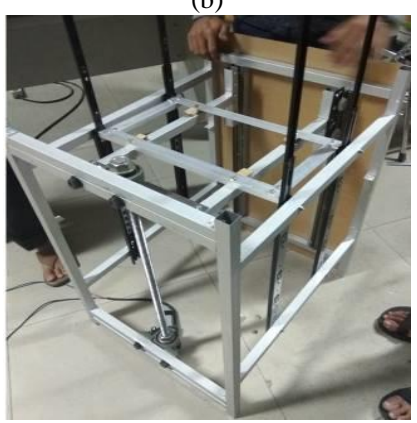

(c)

Gambar 3. Proses pembuatan Mekanik Alat

(a). Perataan permukaan ujung drat galvanis Putih agar sejajar dengan gear saat dilas.

(b). Pengelasan gear pada drat galvanis

(c). Sistem Mekanik Alat yang telah selesai dibuat

Setelah proses pembuatan mekanik alat selesai dilakukan, selanjutnya dilakukan pemasangan rangkaian kontrol (Arduino, driver motor DC, Buzzer), pemasangan sensor ultrasonik, motor DC pada sistem mekanik tersebut. Bentuk fisik alat yang sudah terpasang komponen tersebut dapat dilihat pada Gambar 4.

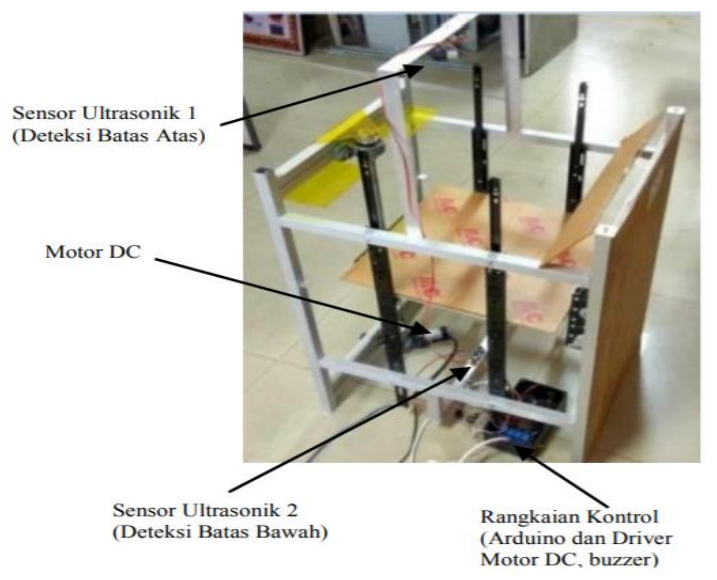

Gambar 4. Pemasangan Rangkaian Kontrol, Sensor, Motor DC dan pada Alat Penampung Buku

Jurnal Sistim Informasi dan Teknologi Vol. 3 No. 2 (2021) 76-81 
Kemudian acrylic penutup dipasang pada semua sisi alat. Dengan demikian proses implementasi sistem dari segi perangkat keras (hardware) telah selesai dilakukan. Selanjutnya dilakukan implementasi sistem dari segi perangkat lunak (software), yaitu dengan membuat program yang alat yang dirancang dengan menggunakan bahasa $\mathrm{C}$ untuk pemrograman Arduino. Setelah program selesai dibuat, program di-upload ke dalam modul Arduino.

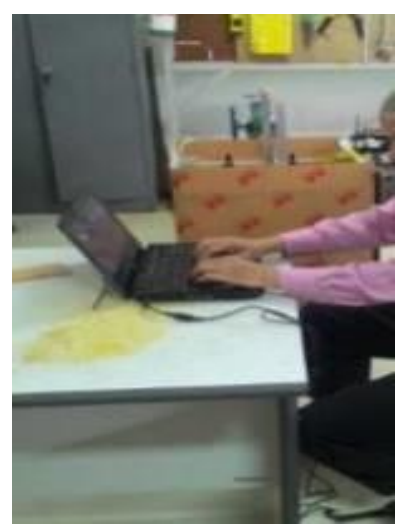

Gambar 5. Proses Pembuatan Program Kendali Peralatan

Selanjutnya peralatan diaktifkan dan dilakukan pengujian baik dari segi perangkat keras (hardware) maupun dari segi perangkat lunak (software).

\subsection{Pengujian Sistem}

Pada tahap ini dilakukan pengujian terhadap sistem yang telah dirancang. Mekanisme pengujian sistem sebagai berikut:

\section{a. Unit Testing}

Pengujian masing-masing unit komponen program untuk meyakinkan bahwa sudah beroperasi secara benar.

b. Module Testing

Pengujian terhadap koleksi unit-unit komponen yang saling berhubungan.

c. Subsystem Testing

Pengujian terhadap koleksi modul-modul yang membentuk suatu subsystem (aplikasi).

d. System Testing

Pengujian terhadap integrasi subsystem, yaitu keterhubungan antar subsystem.

\section{Hasil dan Pembahasan}

Setelah peralatan selesai, maka dilakukan pengujian untuk mengetahui kinerja dari peralatan yang dibangun. Gambaran dari keseluruhan dari penampung buku tersebut dapat dilihat pada Gambar 6.

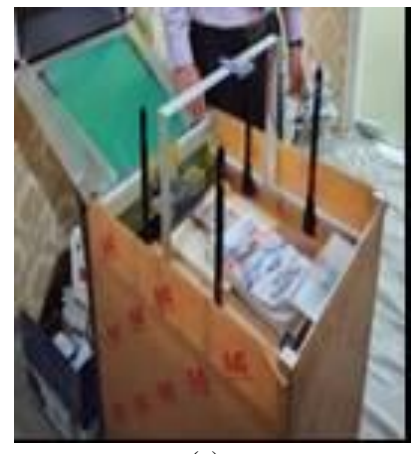

(a)

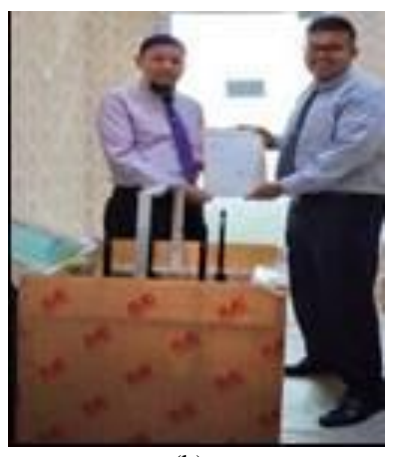

(b)
Gambar 6. Alat Penampung Buku Siap Dioperasikan (a). Tampilan Fisik Alat

(b). Penyerahan Surat Keterangan Penggunaan Alat Penampung Buku Oleh Kepala Pustaka

Pengujian yang dilakukan meliputi pengujian masingmasing bagian input dan output pada blok diagram.

\subsection{Pengujian Rangkaian Tombol Input 1..4}

Pengujian dilakukan dengan mengukur tegangan saat tombol ditekan maupun saat tombol tidak ditekan. Hasil pengujian dapat dilihat pada Tabel 1.

\begin{tabular}{|c|c|c|}
\hline No. & Kondisi Tombol & Tegangan Output (VDC) \\
\hline 1 & Ditekan & $0,00 \mathrm{~V}$ \\
\hline 2 & Tidak Ditekan & $4,99 \mathrm{~V}$ \\
\hline
\end{tabular}

Dari hasil pengujian dapat dilihat bahwa pada saat tombol ditekan, tegangan output yang dihasilkan adalah 0,00VDC. Tegangan ini pada sistem digital dikategorikan sebagai logika '0' (Low). Hal ini disebabkan output rangkaian tombol langsung terhubung ke ground, sedangkan pada saat tombol tidak ditekan, tegangan output rangkaian sebesar 4,99VDC. Pada saat tombol tidak ditekan, output rangkaian langsung terhubung ke sumber tegangan melewati resistor 4,7Kohm. Tegangan ini dalam sistem digital dikategorikan sebagai logika '1' (High). Berdasarkan hasil pengujian tersebut, rangkaian tombol input 1..4 dapat dikatakan bekerja dengan baik, karena memenuhi syarat untuk dibaca secara digital oleh modul Arduino.

\subsection{Pengujian Sensor Ultrasonik}

Pengujian dilakukan dengan membuat program pengukuran jarak menggunakan sensor ultrasonik, kemudian membandingkan hasil pengukuran sensor dengan jarak sebenarnya. Hasil perbandingan dapat dilihat pada Tabel 2 .

Tabel 2. Pengujian Sensor Ultrasonik

\begin{tabular}{rccc}
\hline No. & $\begin{array}{c}\text { Jarak Terukur Oleh } \\
\text { Sensor }(\mathrm{cm})\end{array}$ & $\begin{array}{c}\text { Jarak Sebenarnya } \\
(\mathrm{cm})\end{array}$ & \% Error \\
\hline 1 & 5 & 5,05 & 1,00 \\
2 & 10 & 10,07 & 0,70 \\
3 & 15 & 15,10 & 0,67 \\
4 & 20 & 20,10 & 0,50 \\
5 & 25 & 25,13 & 0,52 \\
6 & 30 & 30,08 & 0,27 \\
7 & 35 & 35,12 & 0,34 \\
8 & 40 & 40,10 & 0,25 \\
9 & 45 & 45,14 & 0,31 \\
10 & 50 & 50,20 & 0,40 \\
11 & 55 & 55,25 & 0,45 \\
12 & 60 & 60,20 & 0,33 \\
\hline
\end{tabular}


Dari kondisi pengukuran pada tabel 2 terlihat bahwa dan turun pada saat beban maksimal $( \pm 22 \mathrm{Kg})$. Proses perbedaan antara jarak terukur oleh sensor dan jarak pengujian dapat dilihat pada Gambar 7. terukur yang sebenarnya hanya terletak pada angka di belakang koma. Persentase error yang didapatkan paling tinggi adalah $1 \%$. Ini tidak begitu berdampak pada pengaturan alat penampung buku batas atas maupun batas bawah. Hal ini disebabkan pada program dibuat toleransi error dalam pengambilan keputusan adalah sebesar $1 \mathrm{~cm}$. Dengan demikian maka dapat dikatakan bahwa rangkaian sensor ultrasonik telah dapat bekerja dengan baik.

\subsection{Pengujian Driver Motor DC}

Pengujian dilakukan dengan melihat langsung arah pergerakan motor DC pada saat logika program diberikan kepada driver Motor DC tersebut. Hasil pengujian dapat dilihat pada Tabel 3.

Tabel 3. Pengujian Driver Motor DC

\begin{tabular}{llll}
\hline No. & \multicolumn{2}{c}{$\begin{array}{c}\text { Logika Yang } \\
\text { Diberikan }\end{array}$} & Kondisi Motor DC \\
\hline 1 & 0 & 0 & Diam / tidak bergerak \\
2 & 1 & 0 & Bergerak searah jarum jam (cw) \\
3 & 0 & 1 & $\begin{array}{l}\text { Bergerak berlawanan arah } \\
\text { dengan jarum jam (ccw) }\end{array}$ \\
\hline
\end{tabular}

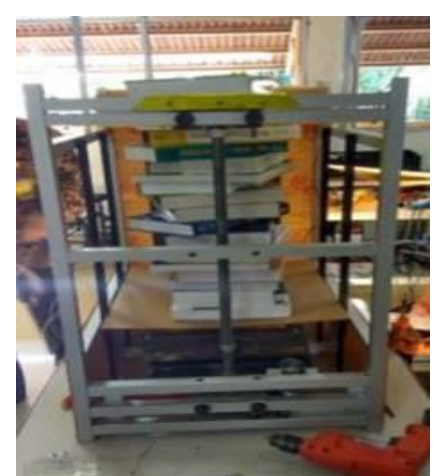

Gambar 7. Proses Pengujian Ketahanan Alat Pada Beban Maksimal

Dari Gambar 7 terlihat bahwa ukuran buku yang diletakkan pada alas penampung buku relatif besar dengan berat rata-rata 750gram s/d 1000gram setiap bukunya. Jumlah buku juga dibuat maksimal dan sudah memenuhi alat penampung. Pengujian dilakukan dengan melihat kemampuan motor DC dalam menurunkan maupun menaikkan alas penampung buku. Ini sengaja dilakukan dalam tahap pengujian, karena Dari kondisi pengukuran pada tabel 3 terlihat bahwa jika pengujian dengan beban maksimal berhasil pada saat input driver motor DC diberikan logika 00, dilakukan, maka ukuran buku yang relatif kecil tidak maka motor tidak bergerak (diam). Pada saat diberikan menjadi masalah lagi bagi sistem mekanik alat. Hasil logika 10, maka motor bergerak searah jarum jam (cw/ pengujian dapat dilihat pada Tabel 5.

clock wise). Sebaliknya pada saat diberikan logika 01 , maka motor bergerak berlawanan arah dengan jarum jam (ccw - counter clock wise). Arah pergerakan ini menyebabkan alas penampung buku bisa bergerak naik dan mundur serta stop (tidak bergerak). Dengan demikian maka dapat dikatakan bahwa rangkaian driver motor DC telah dapat bekerja dengan baik.

\subsection{Pengujian Buzzer}

Pengujian dilakukan dengan memberikan tegangan pada input rangkaian Buzzer berupa logika '0' dan logika ' 1 ', kemudian mendengarkan bunyi yang dihasilkan oleh Buzzer. Hasil pengujian dapat dilihat pada Tabel 4.

Tabel 4. Pengujian Buzzer

\begin{tabular}{lll}
\hline No. & Logika Input & Kondisi Buzzer \\
\hline 1 & $' 0 '$ & Tidak aktif \\
2 & $' 1 '$ & Aktif/Mengeluarkan Suara/bunyi \\
& & yang bisa didengar dalam radius \\
& & \pm 20 meter \\
\hline
\end{tabular}

Dari hasil pengujian dapat dilihat bahwa pada saat logika '0' diberikan, Buzzer tidak aktif (tidak mengeluarkan suara). Sedangkan pada saat logika ' 1 ' diberikan, Buzzer aktif mengeluarkan suara/bunyi yang bisa didengar dalam jarak \pm 20 meter. Berdasarkan hasil pengujian tersebut, rangkaian Buzzer dapat dikatakan bekerja dengan baik, karena memenuhi syarat untuk dijadikan sebagai tanda buku sudah penuh.

\subsection{Pengujian Ketahanan Alat Terhadap Beban Buku}

\begin{tabular}{lcl} 
& \multicolumn{2}{c}{ Tabel 5. Pengujian Ketahanan Beban Alat } \\
\hline No. & Berat Buku $(\mathrm{Kg})$ & Kondisi Alas Penampung Buku \\
\hline 1 & 5 & Mampu bergerak naik / turun \\
2 & 10 & Mampu bergerak naik / turun \\
3 & 15 & Mampu bergerak naik / turun \\
4 & 20 & Mampu bergerak naik / turun \\
5 & 22 & Mampu bergerak naik / turun \\
\hline
\end{tabular}

Dari hasil pengujian dapat dilihat bahwa mulai dari beban $5 \mathrm{~kg}$ s/d $22 \mathrm{~kg}$ (beban maksimal), alas buku mampu bergerak naik maupun turun. Ini membuktikan bahwa sistem mekanik yang digerakkan oleh motor DC telah dapat bekerja dengan baik dan alat sudah siap untuk dioperasikan.

\subsection{Pengujian Pengoperasian Peralatan Secara Keseluruhan}

Pengujian dilakukan dengan melakukan proses pengembalian buku layanan mandiri. Hasil pengujian dapat dilihat pada Gambar 8 .

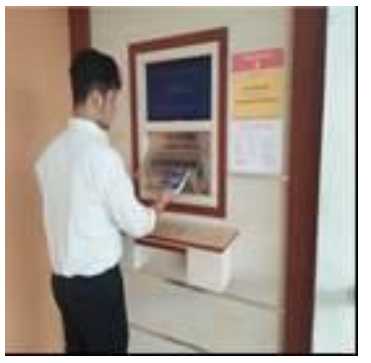

(a)

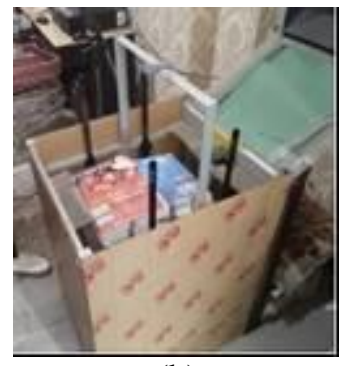

(b)

Pengujian dilakukan dengan melihat langsung pada alat dan kemampuan alas penampung buku bergerak naik 


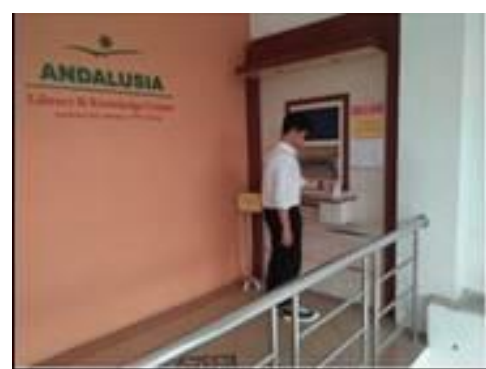

(c)

Gambar 8. Proses Pengujian Sistem Pengembalian Buku Layanan Mandiri Secara Keseluruhan

(a). Buku dimasukkan pada celah book drop

(b). Buku sampai pada alat penampung buku

(c). Peminjam memperoleh resit pengembalian buku

Dari hasil pengujian sistem pengembalian buku layanan mandiri secara keseluruhan dapat dilihat bahwa pada tahap awal si peminjam memasukkan buku pada celah yang ada di book drop (gambar 8.a). Kemudian buku tersebut meluncur jatuh ke alat penampung buku (gambar 8.b). Selanjutnya si peminjam menerima resit bahwa pengembalian buku telah berhasil dilakukan (gambar 8.c). Dari hasil pengujian, alas penampung buku bisa turun secara otomatis setelah buku dimasukkan. Disini program bahasa C yang terdapat pada modul Arduino akan mencek nilai batas atas yang diberikan oleh sensor ultrasonik 1. Pada program dibuat jika jarak batas atas kecil dari $18 \mathrm{~cm}$, maka alas akan diturunkan hingga tercapai jarak $18 \mathrm{~cm}$ kembali. Dengan demikian jika ada buku sebelumnya yang lebih tebal masuk terlebih dahulu, maka buku berikutnya yang lebih tipis tidak menyebabkan perubahan posisi alas penampung buku. Namun perbedaan ketebalan ini maksimum hanya satu buah buku saja. Buku yang masuk berikutnya biasanya akan mempengaruhi perubahan posisi alas penampung buku. Pengujian dilakukan sampai buku penuh. Ini ditandai dengan alas penampung buku sudah mendekati sensor ultrasonik batas bawah. Pada program dibuat jika jarak batas bawah kecil dari $10 \mathrm{~cm}$, maka buzzer aktif untuk memberitahu pustakawan bahwa alat penampung sudah penuh.

\section{Kesimpulan}

Berdasarkan penelitian yang telah dilakukan dapat ditarik kesimpulan bahwa secara keseluruhan peralatan yang dirancang dan dibuat telah dapat bekerja dengan baik. Hal ini didasarkan pada pengujian terhadap masing-masing bagian dalam blok diagram. Disamping itu mekanik sistem juga mememiliki kemampuan untuk menahan beban yang relatif berat, lebih kurang $22 \mathrm{Kg}$. Ini setara dengan buku dengan jumlah antara 30 buah sampai dengan 50 buah buku, tergantung kepada ukuran besar kecilnya buku tersebut. Sebelum dipasang di lokasi, sistem terlebih dahulu telah melewati uji coba pengaktifan selama 3 hari, dari pagi sampai sore hari di Laboratorium Sistem Komputer UPI YPTK Padang. Sampai saat laporan penelitian ini ditulis, alat penampung buku pada sistem layanan mandiri yang dirancang dan dibuat ini alhamdulillah berfungsi dengan baik dan sudah digunakan pada Andalusia Library \& Knowledge Center Universitas Putra Indonesia YPTK Padang selama lebih dari 2 tahun.

\section{Daftar Rujukan}

[1] Supriyo, S. (2015). Pengaruh Buku Teks dan Cetak Terhadap Hasil Belajar di Sma N I Marga Tiga Kabupaten Lampung Timur pada Kelas XIIi. IPS Tahun Pelajaran 2013/2014. PROMOSI (Jurnal Pendidikan Ekonomi), https://doi.org/10.24127/ja.v3i1.145

[2] Mangnga, A. (2015). Peran Perpustakaan Sekolah Terhadap Proses Belajar Mengajar Di Sekolah. Jupiter, 14(1), 38-42

[3] Fatmawati, E. (2018). Identifikasi Faktor-Faktor Penyebab Kerusakan Koleksi Perpustakaan. Edulib, 7(2), 108-119. doi:10.17509/edulib.v7i2.9722

4] Aria, M. Ramdhani, D. \& Firda, M. (2017). Sistem Sirkulasi Buku Perpustakaan Mandiri Berbasis RFID Automated Library Book Circulation System Based on RFID. Prosiding Saintiks FTIK UNIKOM, V.27

[5] Tjandrarini, A. B. \& Lemantara, J. (2015) Pembuatan Prototipe Tempat dan Aplikasi Pengembalian Koleksi Perpustakaan Secara Mandiri. J. Nas. Tek. Elektro dan Teknol. Inf. 4(1), http://dx.doi.org/10.22146/jnteti.v4i1.131

[6] Watkiss, S. (2016). Learn Electronics with Raspberry Pi: Physical Computing with Circuits, Sensors, Outputs, and Projects. Second Edition, Apress

[7] Naf'an, E. (2019. December 6). Akurasi Sistem Penjadwalan Sholat Digital Menggunakan Arduino Sebagai Pengendali. Jurnal Sistim Informasi Dan Teknologi, 1(4), 77-84. https://doi.org/10.35134/jsisfotek.v1i4.25

[8] Naf an, E., Sulaiman, R., Mohamad Ali, N., Priambodo, B., Hazidar, A. H., Kudr Nseaf, A., ... Handriani, I. (2019). Improving the Modelling of Robot Bunker With Camera. Journal of Physics: Conference Series, 1339, 012014. https://doi.org/10.1088/1742-6596/1339/1/012014

[9] N. Anju Latha, B. Rama Murthy, K. Bharat Kumar (2016). Distance Sensing with Ultrasonic Sensor and Arduino. International Journal of Advance Research, Ideas and Innovations in Technology, 2(5), 1-5.

[10]Zakaria, D., Gunawan, T., Somantri, Y., Abdullah, A. G., Widiaty, I., Nandiyanto, A. B. D., ... Arasid, W. (2018). Design of the Liquid Volume Meter Device Using Ultrasonic Waves Based on Microcontroller. IOP Conference Series: Materials Science and Engineering, 384, 012019. https://doi.org/10.1088/1757-899x/384/1/012019

[11] Warren, J. D., Adams, J. \& Molle, H. (2011). Arduino Robotics. Apress. https://doi.org/10.1007/978-1-4302-3184-4

[12] Abbes, M. S., Choley, J.-Y., Chaari, F., Jarraya, A., \& Haddar, M. (Eds.). (2014). Mechatronic Systems: Theory and Applications. Lecture Notes in Mechanical Engineering. https://doi.org/10.1007/978-3-319-07170-1

[13] Team, E. (2019) Lesson 09 Buzzer

[14] Arduino (2019). Arduino Mega 2560 Rev3

[15] Arduino (2019) Arduino Uno Rev3

[16] Oxer, J., \& Blemings, H. (2010). Practical Arduino. https://doi.org/10.1007/978-1-4302-2478-5

[17]Cameron, N. (2019). Arduino Applied. https://doi.org/10.1007/978-1-4842-3960-5 